\title{
The role of green space in the urbanization of Hanoi city
}

\author{
Minh Tuan Le $e^{1, *}$, Thi Anh Tuyet $\mathrm{Cao}^{2}$ and Nguyen Anh Quan Tran ${ }^{3}$ \\ ${ }^{1}$ Moscow State university of Civil Engineering, Yaroslavskoye Shosse, 26, Moscow, 129337, Russia \\ ${ }^{2}$ Moscow State university of geodesy and cartography, Gorokhovsky pereulok, 4, Moscow, 105064 , \\ Russia \\ ${ }^{3}$ Peter the Great Saint-Petersburg Polytechnic university, Polytechnicheskaya, 29, Saint Petersburg, \\ 195251, Russia
}

\begin{abstract}
Rapid urbanization causes significant changes on the earth surface directly and internal itself temperature. The transformation of land use purposes crucially affects the surface temperature and exacerbates the effect of the negative heat island. It is necessary to develope a long-term strategy optimize urban cooling. In this study, the determinated object is Hanoi city - a widen urbanized city in Vietnam. The authors proposed, defined and calculated the concept of cooling efficiency and threshold values. The results show that the surface heat capacity increases in proportion to the reduction of green space. Plots with excess temperature difference of the ground surface of $4.34^{\circ} \mathrm{C}$ with reduced green space.
\end{abstract}

\section{Introduction}

Urbanization is the population movement from rural to urban areas and is often characterized by a density of the urban population, a stream of human activity, masses of buildings and green spaces $[1,2,3]$. The process of urbanization also creates alternative types of natural and semi-natural earth cover for waterproof, closed surfaces, habitat changes, and soil change processes $[4,5]$. The transformation of heat transfer and albedo depends on the type of earth cover. Consequently, the process of rapid urbanization causes the phenomena of the urban microclimate called Urban Heat Island (UHI), one of the primary problems associated with the environment [6].

Studying the amount of radiation and the characteristics of the earth surface, the relationship between the earth cover and temperature is explained clearly [6,7]. Changes in surface temperature are associated differently with different types of earth cover. The temperature of the earth surface increases with the growth of the urbanization index, the distribution of surface temperature is influenced not only by the physical factors of cities, but also by the relationship between the social conditions of the population (for example: income, education) [8]. A number of studies indicate that the incomes of city residents and

\footnotetext{
* Corresponding author: architect290587@gmail.com
} 
the low level of education of the elderly population, often associated with surface temperature, are higher than in other areas $[9,10]$.

The benefits of urban green space have been evaluated by many studies as a method to minimize the effect of UHI. Studies show that urban green spaces have a positive effect on the adaptation of the thermal environment in cities through the mechanism of evaporation and shade provided by green vegetation $[11,12,13]$. The landscape's assets, the structure forming green spaces (for example, the size, shape of the structure) also influence the cooling effect of urban heat islands $[14,15,16]$.

Moreover, with in-depth studies on the cooling effect of green space, researchers have shown that the coefficient between green space and the surface temperature of the Earth is not enough to support in practical urban planning $[17,18]$. The focus of research was the quantitative level of cooling and the intensity of green space. In a study from Bowler, D.E. laid out the results reduce heat to an average temperature with an urban green space of 0.94 ${ }^{\circ} \mathrm{C}$ in the daytime and $1.15^{\circ} \mathrm{C}$ in the evening and the range of green space cooling $500 \mathrm{~m}$ [15]. However, in the case of Japan, a separate study showed that the cooling effect may exceed $300 \mathrm{~m}$, but the cooling range did not exceed $500 \mathrm{~m}$ [19]. In a city at high latitude, Gothenburg, the difference in summer temperature between the park and the construction site is $5.9^{\circ} \mathrm{C}$ and the cooling range reaches more than $1.1 \mathrm{~km}$ from the park border [20], while at low latitudes the cooling range of Mexico reaches more $2 \mathrm{~km}$ [21].

\section{Methods}

\subsection{Study area}

The capital Hanoi after the expansion of administrative borders since 2008 increased to 30 administrative units, including 12 districts with an area of $3344.7 \mathrm{~km}^{2}$, the population also increased by almost 7 million people. In addition, immigrants accounted for a huge amount to develop infrastructure, housing expands, resulting in the phenomenon of urban heat island contribute to climate change in Vietnam.

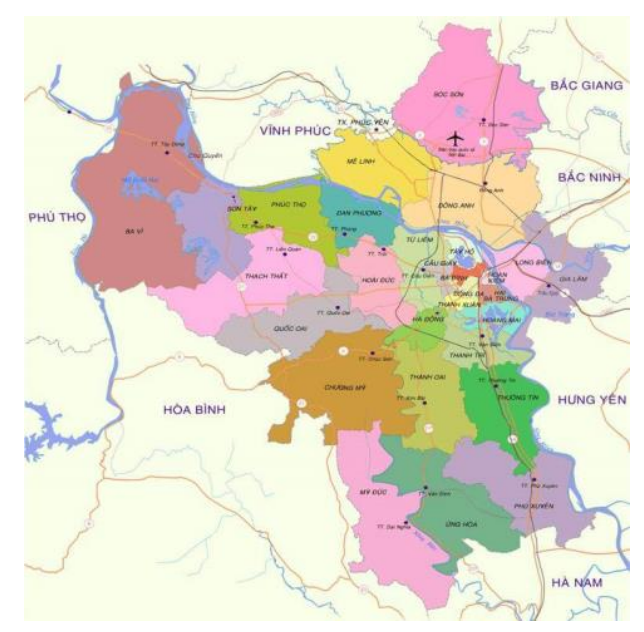

Fig. 1. Scheme of the city of Hanoi. 


\subsection{Definition and calculation of cooling efficiency}

Sustainable urban planning not only satisfies the demand for quality of life and the comfort of people, but also ensures the sustainable development of cities, especially in rapidly urbanized areas [22]. In this context, in order to more effectively balance urban development and minimize the influence of the urban heat island, it is important to optimize cooling efficiency with the help of green spaces [23].

Some studies show that the cooling effect of green space decreases in distance at the border and disappears at a certain distance $[15,20]$. To determine the cooling effect of an array of green spaces is the temperature difference between the surface area of the earth between the inner border and the urban area around. Correspondingly, to determine the level of maximum cooling is the distance between the edge of the green space and the first reference point of the temperature reduction in comparison with the temperature in the green space (Fig. 3). The turning point is the maximum surface temperature, which is considered the cooling rate.

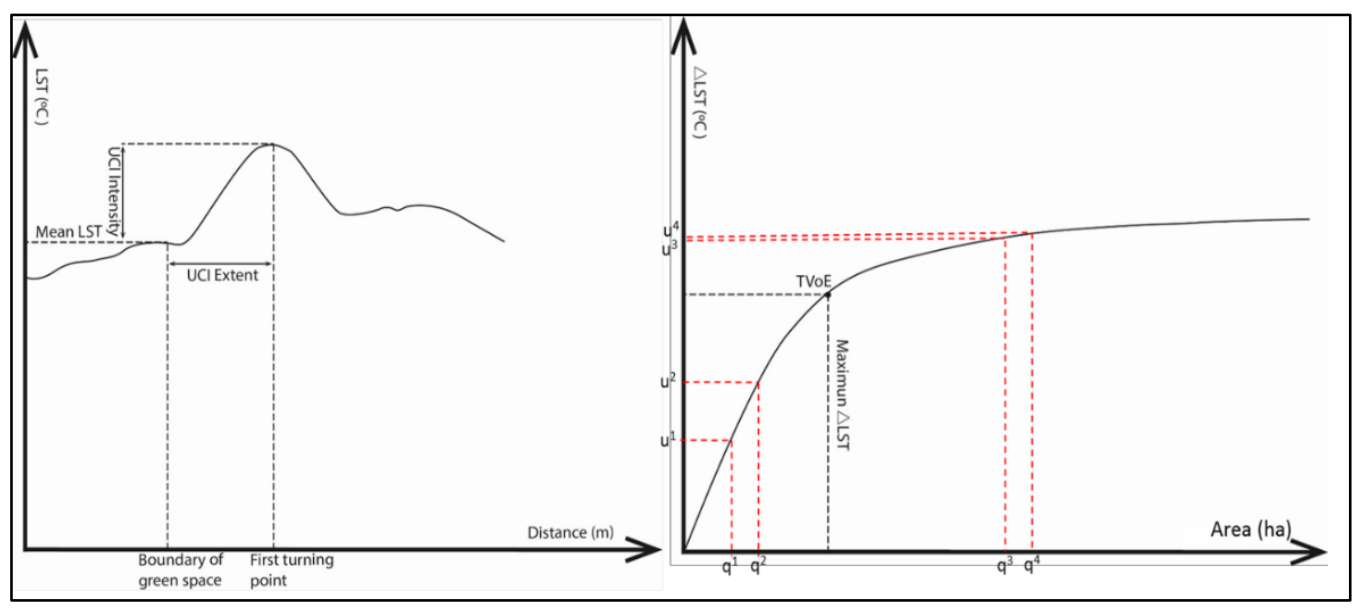

Fig. 2. Curve concept of the cooling effect of green space [24].

The cooling efficiency is defined as the curve between the area (variable) and the maximum cooling intensity of each green zone. In Figure 2, if the size of the green zone increases from q1 to q2, the change in temperature of the soil surface (U2-U1) will be significant. However, if the size of green space increases from $\mathrm{q} 3$ to $\mathrm{q} 4$, the surface temperature rises slightly (U4-U3), although the change in area remains the same. Therefore, an effective threshold value (TVoE) will be proposed. At a certain point, the cooling effect will become stable in a certain range.

\section{Result}

\subsection{Change of land surface from 2007 to 2017 (Hanoi).}

The results of satellite imaging using the method of remote sensing show that over 15 years, from 2007 to 2017, the area of urban areas (building land) has increased 1.65 times (Table 1 and Figure 4). In Figure 3, the area of 12 urban areas thrives in the direction of spreading from the central area and concentrating on all sides, especially along the main roads in the central border. 
3a - 24.05 .2007

3b - 01.08 .2012
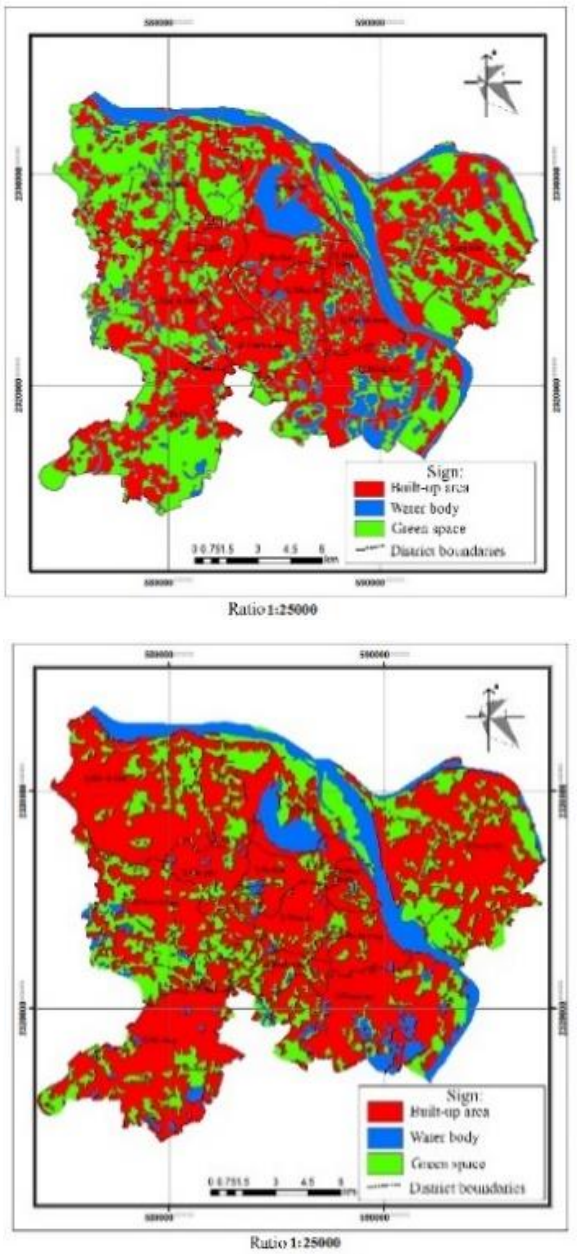

3c - 04.06.2017

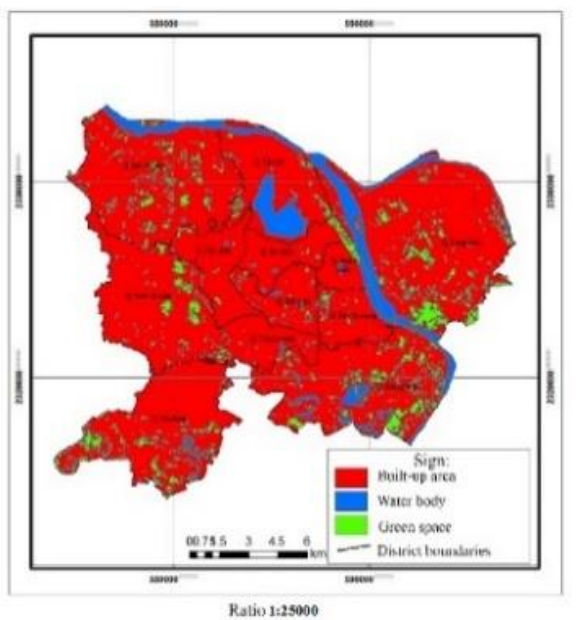

Fig. 3. The current state of surface coating of the city of Hanoi from 2007 to 2017 (using remote sensing technology to solve mathematical images by satellite Landsat $5,7,8$ ) 
Table 1. Type of land using statistics

\begin{tabular}{|c|c|c|c|c|c|c|c|}
\hline \multirow[b]{2}{*}{ No. } & \multirow[b]{2}{*}{$\begin{array}{c}\text { Type of land } \\
\text { used }\end{array}$} & \multicolumn{2}{|c|}{$24 / 05 / 2007$} & \multicolumn{2}{|c|}{$01 / 08 / 2012$} & \multicolumn{2}{|c|}{$04 / 06 / 2017$} \\
\hline & & $\begin{array}{c}\text { Square area } \\
\text { (ha) }\end{array}$ & $\%$ & $\begin{array}{c}\text { Square area } \\
\text { (ha) }\end{array}$ & $\%$ & $\begin{array}{c}\text { Square area } \\
\text { (ha) }\end{array}$ & $\%$ \\
\hline 1 & Built-up area & 14989,56 & 51,53 & 19413,23 & 66,74 & 24705,81 & 84,9 \\
\hline 2 & Water body & 3497,19 & 12,02 & 3113,93 & 10,71 & 2082,24 & 7,16 \\
\hline 3 & Green space & 10601,16 & 36,45 & 6560,75 & 22,55 & 2299,86 & 7,91 \\
\hline & Total & 29087,91 & 100 & 29087,91 & 100 & 29087,91 & 100 \\
\hline
\end{tabular}

In general, the results (Fig. 4) show a plot of land for development in terms of scale and percentage of soil by type of use from 2007 to 2017. The growth rate of building land quickly fits the context of rapid urbanization in the city of Hanoi. In particular, the share of urban green space decreased from 10601.16 hectares (36.45\%) to 2299.86 hectares $(7.91 \%)$ in the period 2007-2017. This is the most significant change in the proportion of landscaping.

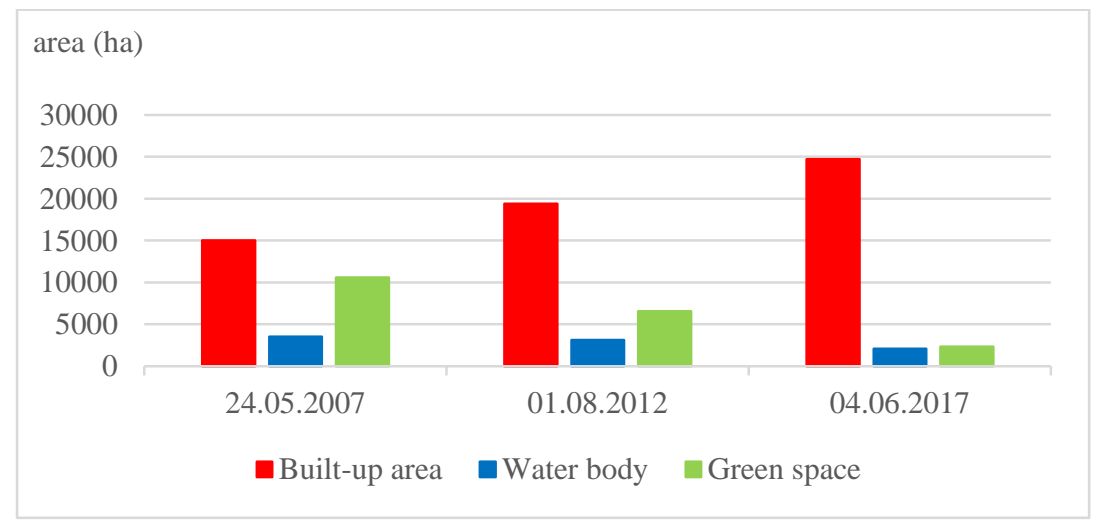

Fig.4. Graph of green space change in urban areas by year.

\subsection{Assessing the correlation between surface temperature and urbanization}

The linear regression equations are used to find the relationship between temperature, changing the process of urbanization, with variables including: surface temperature ( $\mathrm{T}$ land surface temperature) - dependent variable, three factors based on satellite images considered three independent variables of urbanization process associated with the transition surfaces with $\mathrm{B}$ - percentage of the construction site; $\mathrm{W}$ - percent of land and water surface; $\mathrm{G}$ - percentage of the ground cover plants. From statistical data that will be extracted directly from satellite images for the variables land surface temperature, Built-up area\%, Water body\% and Green space\%. These are the areas of land, water and plants that are converted to percentages. Linear regression equation sentences:

$$
T_{L S T}=35,98+0,02 * B-0,08 * W-0,07 * G
$$


Calculated results is showed in the table 2 below:

Table 2. Results of linear regression calculations determine the coefficient of construction land, water surface and vegetation.

\begin{tabular}{|c|c|c|c|c|c|c|c|c|}
\hline SUMMARY OUTPUT & & & & & & & & \\
\hline \multicolumn{9}{|c|}{ Regression Statistics } \\
\hline Multiple R & 0.915710981 & & & & & & & \\
\hline R Square & 0.8385266 & & & & & & & \\
\hline Adjusted R Square & 0.823388469 & & & & & & & \\
\hline Standard Error & 0.084693824 & & & & & & & \\
\hline Observations & 36 & & & & & & & \\
\hline \multicolumn{9}{|l|}{ ANOVA } \\
\hline & df & ss & MS & $\mathbf{F}$ & Significance $F$ & & & \\
\hline Regression & 3 & 1.19198097 & 0.39732699 & 55.3916852 & $9.0845 \mathrm{E}-13$ & & & \\
\hline Residual & 32 & 0.229537405 & 0.007173044 & & & & & \\
\hline \multirow[t]{2}{*}{ Total } & 35 & 1.421518375 & & & & & & \\
\hline & Coefficients & Standard Error & t Stat & P-value & Lower $95 \%$ & Upper $95 \%$ & Lower $95,0 \%$ & Upper $95,0 \%$ \\
\hline Intercept & 35.98558 & 0.02528 & 1423.48826 & 0.00000 & 35.93409 & 36.03708 & 35.93409 & 36.03708 \\
\hline B & 0.01914 & 0.00427 & 4.48636 & 0.00009 & 0.01045 & 0.02783 & 0.01045 & 0.02783 \\
\hline w & -0.07978 & 0.01962 & -4.06594 & 0.00029 & -0.11975 & -0.03981 & -0.11975 & -0.03981 \\
\hline G & -0.06724 & 0.00838 & -8.02735 & 0.00000 & -0.08430 & -0.05018 & -0.08430 & -0.05018 \\
\hline
\end{tabular}

\subsection{Assessing the correlation between surface temperature and urbanization}

Lakes and rivers in Hanoi play an important role in the landscape of the city, which reduce the ambient temperature in cities in the summer. Green space's area has been replaced by the building area which is the result of population growth, causing flooding and environmental pollution. Rivers and lakes have lost a role in regulating rainwater and microclimate. The problem of lakes in the city of Hanoi:

+ The environment around the lakes is polluted.

+ In the master plan of the city there are no standards for the lake system.

Table 2 shows that in summer the average intensity of heat reduction was $3{ }^{\circ} \mathrm{C}$ (the highest intensity of heat reduction in lake Bay Mau was $5.2{ }^{\circ} \mathrm{C}$, and the lowest intensity of heat reduction in lake De De was $1^{\circ} \mathrm{C}$ ). The average heating reduction distance was $714 \mathrm{~m}$ (the longest distance in the Bay Mau lake is $1400 \mathrm{~m}$, the closest distance in the lake Bo De and Hai Ba Trung is $200 \mathrm{~m}$ ). In winter, the average intensity of heat reduction was $1.1{ }^{\circ} \mathrm{C}$ (the highest intensity of heat reduction in lake $2^{\text {nd }}$ Hoan Kiem, and the lowest intensity of heat reduction in lake Lang $0.5^{\circ} \mathrm{C}$ ); the average heating reduction distance was $733 \mathrm{~m}$ (the longest distance in the lake Thanh Cong, Thanh Nhan, Bay Mau 1400m, the nearest distance in the lake Lang $200 \mathrm{~m}$ ). In summer, the average intensity of heat reduction is higher than in winter.

Table 3. Statistics of techniques for the intensity of heat reduction (maximum) and the distance of heat reduction (maximum) in the summer and winter period in the region of 21 lakes.

\begin{tabular}{|c|c|c|c|c|c|c|c|c|}
\hline \multirow[t]{2}{*}{ No } & \multirow{2}{*}{$\begin{array}{l}\text { Territory } \\
\text { (green space } \\
\text { patches) }\end{array}$} & \multirow{2}{*}{$\begin{array}{l}\text { Square } \\
\text { (ha) }\end{array}$} & \multirow{2}{*}{$\begin{array}{l}\text { Perimete } \\
\mathbf{r} \\
\text { (m) }\end{array}$} & \multirow{2}{*}{$\begin{array}{l}\text { Indicator } \\
\mathbf{S I}^{2} \\
(\mathbf{m} / \mathbf{h a})\end{array}$} & \multicolumn{2}{|c|}{ Summer } & \multicolumn{2}{|c|}{ Winter } \\
\hline & & & & & $\begin{array}{l}\Delta \mathbf{L S T} \\
\left({ }^{\circ} \mathrm{C}\right)\end{array}$ & $\begin{array}{l}\text { Distance } \\
\text { (m) }\end{array}$ & $\begin{array}{l}\Delta \mathbf{L S T} \\
\left({ }^{\circ} \mathrm{C}\right)\end{array}$ & $\begin{array}{l}\text { Distan } \\
\text { ce } \\
\text { (m) }\end{array}$ \\
\hline 1 & Hoan Kiem & 15,32 & 1671,73 & 109 & 3,6 & 700 & 2 & 700 \\
\hline 2 & Huy Van & 1,31 & 446,58 & 341 & 1,7 & 300 & 0,9 & 400 \\
\hline 3 & Thu Le & 12,95 & 1669,06 & 129 & 3,7 & 1200 & 1,4 & 1400 \\
\hline 4 & Thanh Cong & 5,49 & 960,29 & 175 & 3,2 & 900 & 1,2 & 1400 \\
\hline 5 & Xa Dan & 3,84 & 760,34 & 198 & 3,6 & 700 & 1,4 & 500 \\
\hline
\end{tabular}




\begin{tabular}{|l|l|l|l|l|l|l|l|l|}
\hline 6 & Kim Lien & 2,01 & 631,36 & 314 & 1,6 & 500 & 0,7 & 500 \\
\hline 7 & Giang Vo & 7,17 & 1003,6 & 140 & 4 & 1200 & 1 & 700 \\
\hline 8 & Ho Tay & 506,27 & 20553,46 & 41 & 3,3 & 1000 & 1,7 & 1200 \\
\hline 9 & Ngoc Khanh & 3,63 & 767,89 & 212 & 1,7 & 400 & 0,7 & 300 \\
\hline 10 & Lang & 1,63 & 677,53 & 416 & 2,4 & 600 & 0,5 & 200 \\
\hline 11 & Dong Da & 13,61 & 1832,66 & 135 & 4,5 & 1100 & 1,2 & 900 \\
\hline 12 & Bay Mau & 26,05 & 2130,89 & 82 & 5,2 & 1300 & 1,3 & 1400 \\
\hline 13 & Thien Quang & 6,79 & 1079,59 & 159 & 4 & 700 & 1,2 & 700 \\
\hline 14 & Hai Ba Trung & 1,07 & 384,18 & 359 & 1,5 & 200 & 0,7 & 300 \\
\hline 15 & Thanh Nhan & 7,83 & 1317,13 & 168 & 4,1 & 900 & 1,1 & 1400 \\
\hline 16 & Giap Bat & 1,56 & 542,78 & 348 & 2,3 & 600 & 1,3 & 800 \\
\hline 17 & Den Lu & 4,97 & 1062,99 & 214 & 2,4 & 600 & 1 & 300 \\
\hline 18 & Linh Quang & 2,07 & 556,13 & 269 & 3 & 500 & 0,8 & 300 \\
\hline 19 & Nghia Tan & 4,98 & 931,89 & 187 & 3,7 & 800 & 1,2 & 700 \\
\hline 20 & Le Trong Tan & 2,94 & 640,95 & 218 & 2,7 & 600 & 1,6 & 600 \\
\hline 21 & Bo De & 2,02 & 779,74 & 386 & 1 & 200 & 0,8 & 700 \\
\hline Average value: & 30,17 & 1923,85 & 219,05 & 3,01 & 714,29 & 1,13 & 733,33 \\
\hline
\end{tabular}

Firstly, choosing 21 green space patches in 2016 to calculate the cooling extent and intensity of each green space patch, as defined above. Additionally, it is neccesary to quantify the cooling efficiency of green spaces. The results indicate that the bigger size of green space, the lower the cooling efficiency (Fig. 5). The gradient of the model curve is very steep on the left- hand side of Fig. 5, which means that the cooling efficiency of green spaces increases with the size sharply. On the right-hand side of Fig. 5, the gradient is low, which means that the cooling efficiency is diminished and stable. The TVoE has been calculated at 1,0749 ha. The formula of the cooling efficiency curve of green space is: $y=$ $1,0749 \ln (\mathrm{x})+263,46(\mathrm{R} 2=0.72)$.
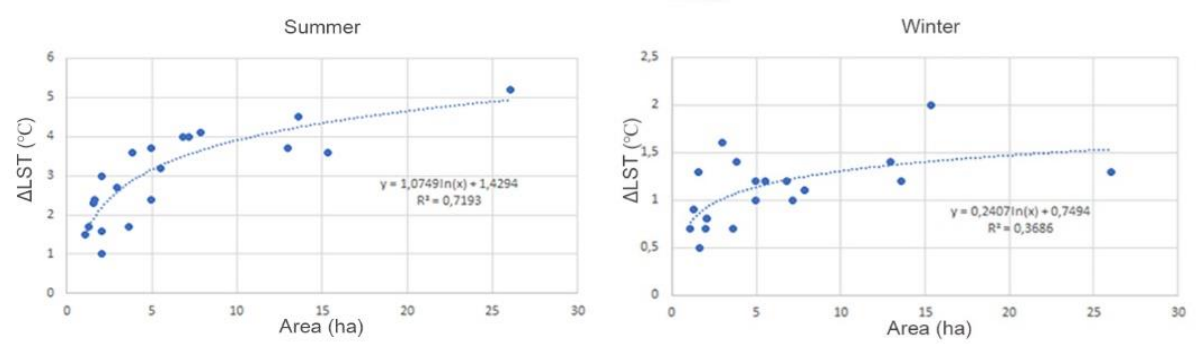

Fig.5. Graph of the relationship between the average intensity of heat reduction $\left({ }^{\circ} \mathrm{C}\right)$ and the green space area (ha)

Based on a graph showing the relationship between thermal intensity and the dimension of green space, a non-linear relationship is derived (showed on Fig. 5). The intensity of heat reduction is proportional to the increase in the size of the green space. A nonlinear model with independent measurement can explain the change in the average intensity of heat reduction in summer by $71.93 \%$ and the change in the average intensity of heat reduction in winter by $36.86 \%$. Studies show that the size of green space is an important factor influencing the intensity of heat reduction. 

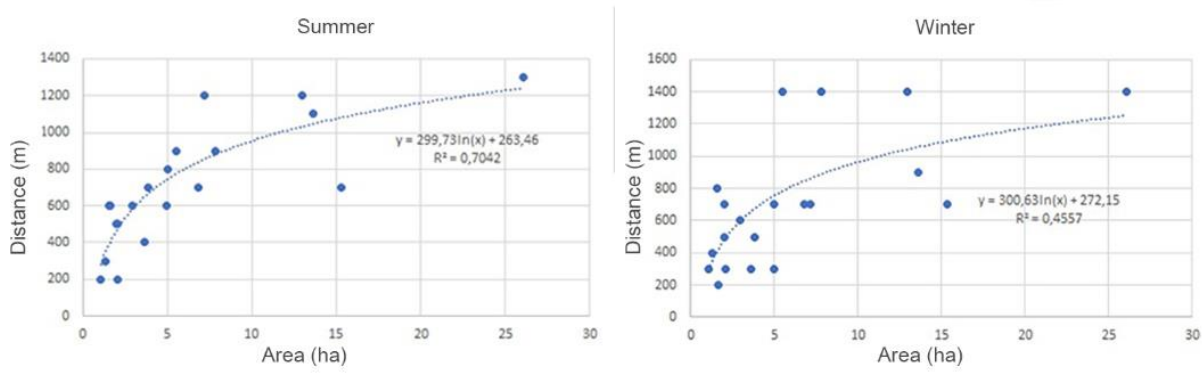

Fig.6. Graph of the relationship between distances decreasing in heat (m) and the area of green space (ha)

Figure 6 shows that increasing the area of green space contributes to an increase in the cooling range of urban areas. The nonlinear model with the size of green space is an independent variable that can explain $70.42 \%$ for summer distance variation and $45.57 \%$ for distance variation in winter. It implies that increasing the size of green space in urban areas also contributes to the increase in the temperature reduction area for urban areas around green space.
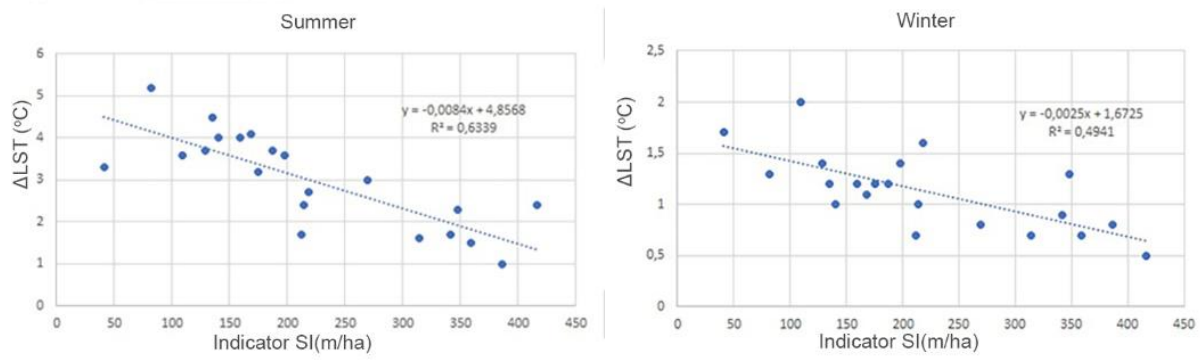

Fig.7. Graph of the relationship between the average intensity of heat reduction $\left({ }^{\circ} \mathrm{C}\right)$ and the shape indicator of the green space $(\mathrm{m} / \mathrm{ha})$

In Fig. 7, it is shown that the relationship between the intensity of heat reduction and the shape indicator of the green space is a linear inverted system. When the SI index increases, the intensity of heat reduction decreases. Therefore, in order to increase the intensity of the decrease in the heat of the green space, it is necessary to decrease the SI index by increasing the area of the green space.

\section{Conclusion}

This study identified changes either on the earth surface temperature or in earth temperature itself within the rapid urbanization process. Hanoi city was selected as a case study to analyze the patterns, dynamics, and correlations. The caculated result indicates the earth surface temperature values increased with increasing proportion of built-up land and sharply decreasing the proportion of green space from 2007 to 2017 . In this case, the areas with surface temperature differences exceeded $4.34{ }^{\circ} \mathrm{C}$ where green spaces are sparse. Due to the significant decrease of green spaces in the rapid urbanization process, it is essential to consider how to maximize the cooling effect of green spaces. There are 2 concepts mentioned which are the "law of diminishing marginal utility" and "cooling efficiency". The paper referred the concept of cooling efficiency and in Hanoi city case, the TVoE 
index of 1.0749 ha has been found. The substantially increased earth surface temperature happened mostly in the areas where the green space areas had been transformed into builtup lands and other lands. Based on the above analyses, these results may mostly explain why Hanoi has become one of the city with highest temperature in Vietnam since the beginning of the 21 st century.

The correlation regression equation between variables shows that the area of construction land is positively impacted with changes in surface temperature, green space and water body, adversely affecting the variation in surface temperature. Therefore, this paper aims proposing the basis for urban design planning planners.

\section{References}

1. Foley, J.A., DeFries, R., Asner, G.P., Barford, C., Bonan, G., Carpenter, S.R., Chapin, F.S., Coe, M.T., Daily, G.C., Gibbs, H.K., Global consequences of land use science 309, 570-574 (2005)

2. Forman, R.T., Urban ecology principles: are urban ecology and natural area ecology really different? Landscape Ecology, 31, 1653-1662(2016)

3. Grimm, N.B., Faeth, S.H., Golubiewski, N.E., Redman, C.L., Wu, J., Bai, X., Briggs, J.M., Global change and the ecology of cities, science 319, 756-760, (2008)

4. Fu, P., Weng, Q., A time series analysis of urbanization induced land use and land cover change and its impact on land surface temperature with Landsat imagery. Remote Sensing of Environment, 175, 205-214, (2016)

5. Voogt, J.A., Oke, T.R., Thermal remote sensing of urban climates. Remote sensing of environment, 86, 370-384, (2003)

6. Oke, T.R., Boundary layer climates. Routledge, London and New York (2002)

7. Forman, R.T., Urban ecology: science of cities. Cambridge University Press (2014)

8. Huang, G., Cadenasso, M.L., People, landscape, and urban heat island: dynamics among neighborhood social conditions, land cover and surface temperatures. Landscape Ecology, 31, 2507-2515, (2016)

9. Buyantuyev, A., Wu, J., Urban heat islands and landscape heterogeneity: linking spatiotemporal variations in surface temperatures to land-cover and socioeconomic patterns. Landscape ecology, 25, 17-33, (2010)

10. Klinenberg, E., Heat wave: A social autopsy of disaster in Chicago. University of Chicago Press (2015)

11. Jaganmohan, M., Knapp, S., Buchmann, C.M., Schwarz, N., The bigger, the better. The influence of urban green space design on cooling effects for residential areas. Journal of Environmental Quality, 45, 134-145, (2016)

12. Santamouris, M., Cooling the cities-a review of reflective and green roof mitigation technologies to fight heat island and improve comfort in urban environments. Solar Energy, 103, 682-703, (2014)

13. Žuvela-Aloise, M., Koch, R., Buchholz, S., Früh, B., Modelling the potential of green and blue infrastructure to reduce urban heat load in the city of Vienna. Climatic Change, 1-14 (2016)

14. Akbari, H., Kolokotsa, D., Three decades of urban heat islands and mitigation technologies research. Energy and Buildings, 133, 834-842, (2016)

15. Bowler, D.E., Buyung-Ali, L., Knight, T.M., Pullin, A.S., Urban greening to cool towns and cities: A systematic review of the empirical evidence. Landscape and urban planning, 97, 147-155, (2010)

16. Monteiro, M.V., Doick, K.J., Handley, P., Peace, A., The impact of greenspace size on the extent of local nocturnal air temperature cooling in London. Urban Forestry \& Urban Greening, 16, 160-169, (2016) 
17. Sun, R., Chen, L., How can urban water bodies be designed for climate adaptation? Landscape and Urban Planning, 105, 27-33, (2012)

18. Yu, Z.W., Guo, Q.H., Sun, R.H., Impact of urban cooling effect based on landscape scale: A review. Chinese Journal of Applied Ecology, 26, 636-642, (2015)

19. Hamada, S., Ohta, T., Seasonal variations in the cooling effect of urban green areas on surrounding urban areas. Urban Forestry \& Urban Greening, 9, 15-24 (2010)

20. Upmanis, H., Eliasson, I., Lindqvist, S., The influence of green areas on nocturnal temperatures in a high latitude city (Göteborg, Sweden). International journal of climatology, 18, 681-700(1998)

21. Jauregui, E., Influence of a large urban park on temperature and convective precipitation in a tropical city. Energy and buildings, 15, 457-463, (1991)

22. Akbari, H., Kolokotsa, D.,Three decades of urban heat islands and mitigation technologies research. Energy and Buildings, 133, 834-842, (2016)

23. Yu, Z., Guo, X., Jørgensen, G., Vejre, H., How can urban green spaces be planned for climate adaptation in subtropical cities? Ecological Indicators, 82, 152-162, (2017)

24. Zhaowu Yu, Xieying Guo, Yuxi Zeng, Motoya Koga, Henrik Vejre. Variations in land surface temperature and cooling efficiency of green space in rapid urbanization: The case of Fuzhou city, China. Urban Forestry \& Urban Greening, 29, 113-121, (2018) 